\title{
Tensile bond strength of indirect composites luted with three new self-adhesive resin cements to dentin
}

\author{
Cafer TÜRKMEN ${ }^{1}$, Meral DURKAN²${ }^{2}$, Hale CiMiLLi ${ }^{3}$, Mustafa ÖKSÜZ ${ }^{4}$
}

1- DDS, PhD, Professor, Department of Operative Dentistry, Faculty of Dentistry, Marmara University, Istanbul, Turkey.

2- DDS, PhD, Lecturer, Department of Operative Dentistry, Faculty of Dentistry, Marmara University, Istanbul, Turkey.

3- DDS, PhD, Associate Professor, Department of Endodontics, Faculty of Dentistry, Marmara University, Istanbul, Turkey.

4- PhD, Associate Professor, Department of Metal Education, Polymer Division, Faculty of Technical Education, Istanbul, Turkey.

Corresponding address: Cafer Türkmen - Marmara University - Dentistry Faculty - Dept. of Operative Dentistry - Büyük Çiftlik sk No.6, 34365 - Nişantaşı İstanbul - TÜRKIYE - Phone: +90 2122319120 - Fax: +90 2122465247 - e-mail: caferturkmen@marmara.edu.tr - caferturkmen@yahoo.com

Received: August 06, 2009 - Modification: April 30, 2010 - Accepted: October 26, 2010

\section{ABSTRACT}

$\mathrm{O}$ bjective: The aims of this study were to evaluate the tensile bond strengths between indirect composites and dentin of 3 recently developed self-adhesive resin cements and to determine mode of failure by SEM. Material and Methods: Exposed dentin surfaces of 70 mandibular third molars were used. Teeth were randomly divided into 7 groups: Group 1 (control group): direct composite resin restoration (Alert) with etch-and-rinse adhesive system (Bond 1 primer/adhesive), Group 2: indirect composite restoration (Estenia) luted with a resin cement (Cement-It) combined with the same etch-and-rinse adhesive, Group 3: direct composite resin restoration with self-etch adhesive system (Nano-Bond), Group 4: indirect composite restoration luted with the resin cement combined with the same self-etch adhesive, Groups 5-7: indirect composite restoration luted with self-adhesive resin cements (RelyX Unicem, Maxcem, and Embrace WetBond, respectively) onto the nonpretreated dentin surfaces. Tensile bond strengths of groups were tested with a universal testing machine at a constant speed of $1 \mathrm{~mm} / \mathrm{min}$ using a $50 \mathrm{kgf}$ load cell. Results were statistically analyzed by the Student's t-test. The failure modes of all groups were also evaluated. Results: The indirect composite restorations luted with the self-adhesive resin cements (groups 5-7) showed better results compared to the other groups $(p<0.05)$. Group 4 showed the weakest bond strength $(p>0.05)$. The surfaces of all debonded specimens showed evidence of both adhesive and cohesive failure. Conclusion: The new universal selfadhesive resins may be considered an alternative for luting indirect composite restorations onto non-pretreated dentin surfaces.

Key words: Bond. Composite resin. Cementation. Dentin.

\section{INTRODUCTION}

The physical properties of composite restorations are improved when the composite is free of voids, and the resin matrix is maximally polymerized. Generating dense, well-cured restorations is best accomplished in the dental laboratory using devices that polymerize the composite under pressure, vacuum, inert gas, intense light, heat or a combination of these conditions ${ }^{15,28}$.

Indirect composites are used in an attempt to overcome some shortcomings of direct composite resin restorations, such as polymerization shrinkage and degree of conversion. Material manipulation out of the mouth allows better proximal contacts, morphology, and adjustment of the occlusal surface. Clinical indications for indirect composite restorations are based on the evaluation of the remaining tooth structure, intraoral conditions, and $\operatorname{cost}^{15,23,28}$.

Laboratory-processed composite inlays/onlays are more resistant to occlusal wear than direct composites, particularly in occlusal contact areas. They offer easy adjustment, low wear of the opposing dentition, good esthetics, and potential 
for repair. Moreover, extraoral polymerization allows higher conversion rate, thus enhancing the composite mechanical properties. They are less wear-resistant than ceramic restorations, however, and might offer more resistance to debonding at interfaces than ceramic restorations. Processed composite restorations are indicated when (1) maximum wear resistance is desired from a composite restoration, (2) achievement of proper contours and contacts would be difficult otherwise, and (3) a ceramic restoration is not indicated because of concerns about wear of the opposing dentition. Regarding the last-mentioned, the indirect composite likely would cause less wear of the opposing dentition than a similar ceramic restoration ${ }^{1,16,27,28}$. The internal surface of indirect restorations can be treated with sandblasting, hydrofluoric acid or silane coupling agents, and with the combination of these treatments. The air-abrasion technique produces a rough surface, while silane creates a chemical adhesion between the inorganic fillers and the organic matrix of the bonding agent. The hydrofluoric acid has been used to etch all-ceramic restorations, however, its effects on different filler particles of composite resins have not been effective in producing high bond strengths of resin cement bonded to indirect composite restorations ${ }^{27}$.

Tooth-colored inlays, onlays, veneers and crowns are now routinely bonded to the tooth substrate via the use of adhesive resin cements. Adhesive resin cements have the ability to bond to both tooth structure and restoration. The integration produces reinforcement of both structures, and reduces microleakage at the restoration-tooth interface, postoperative sensitivity, marginal staining and recurrent caries.

The internal surface of indirect restorations can be treated with sandblasting, hydrofluoric acid or silane coupling agents, or a combination of these treatments ${ }^{16}$. The air-abrasion technique produces a rough surface, while silane creates a chemical adhesion between the inorganic fillers and the organic matrix of the bonding agent. Hydrofluoric acid has been used to etch all-ceramic restorations, however, its application to various composite resin filler particles has been reported to not increase bond strengths of resin cements to indirect composite restorations ${ }^{27}$.

Several other laboratory-processed composites have been introduced in recent years. These are called polymer glasses, filled polymers, or ceramicoptimized resins ("ceromers"). Some manufacturers have recommended their use not only for inlays/ onlays and some single-unit crowns, but also with fiber reinforcement, for splints and short-span fixed partial dentures. The long-term clinical performance of such applications however is unproven ${ }^{28}$.
An adhesive system is used to bond the luting agent to the tooth substrate. Currently, all adhesives are categorized as either etch-and-rinse (also referred to as total-etch) or self-etch adhesives. A multi-step application technique is time consuming and rather technique sensitive, and consequently may compromise bonding effectiveness. Moreover, because of the complex nature of the anatomical structure of the dentin, its etch pattern may differ from that of the enamel and may, as a result, affect the bonding of adhesive materials ${ }^{16,26}$. Three selfadhesive universal resin cements (SRCs): RelyX Unicem, Maxcem, Embrace Wet Bond, have been recently introduced. They require no surface pretreatment. They are based on a new monomer, filler and initiation technology. The manufacturers support that the organic matrix consists of newly developed multifunctional phosphoric acid methacrylates. The phosphoric acidic methacrylates can react with the basic fillers in the luting cement and the hydroxyapatite of the hard tooth tissue ${ }^{11,16}$.

Resin luting agent should provide bond strengths need to be sufficient to resist stress generated by its polymerization shrinkage. Bond strengths also depend on the adhesive capacity to various dental substrates $^{20}$. Adhesive capacity is normally evaluated in vitro by shear and tensile tests $2,4,6,8,12,17,19,20,23$.

Several in vitro studies $8,12,17,20,23,25$ reported the tensile bond strength of different adhesive systems used in combination with a luting composite to dentin. Little information, however, is available in the literature with regard to the tensile bond strength of the indirect composite restoration to dentin.

The purpose of this study was to assess the tensile bond strength of indirect composite restorations cemented to dentin with these three new SRCs, etch-and-rinse, and self-etch adhesive systems using direct posterior composite restorations and $5^{\text {th }}$ generation bonding agents as controls. The surfaces were examined by scanning electron microscopy (SEM) to ascertain failure mode and to morphologically examine the conditioning of the adhesive interface between the tooth and resin before bonding.

\section{MATERIAL AND METHODS}

Specimen selection and involved materials Seventy intact, non-carious, unrestored human third molars, extracted for therapeutic reasons in patients (age range 20-40 years), were stored in an aqueous solution of $0.5 \%$ chloramine $\mathrm{T}$ at $4^{\circ} \mathrm{C}$ for up to 30 days. The teeth were embedded in chemically cured $2 \times 2 \times 2 \mathrm{~cm}$ acrylic resin blocks in such a way that they projected from approximately $2 \mathrm{~mm}$ above the dentinoenamel junction. These unmounted parts of the tooth crowns were then cut 
by a diamond cylindrical bur parallel to the acrylic resin block surface. The specimens were randomly divided into 7 experimental groups.

\section{Preparation of the indirect composite blocks}

Indirect composite restorative materials were manufactured using a Estenia ${ }^{\mathrm{TM}}$ (Kuraray Dental, Osaka, Japan). A cylindrical Teflon mold $5 \mathrm{~mm}$ deep and $5 \mathrm{~mm}$ in diameter was made. The indirect composite restorative materials were placed into this mold in two increments and each increment was light-cured for $180 \mathrm{~s}$ with an Estenia polymerization device (CS-110 light and heat curing unit, Kuraray Dental, Osaka, Japan). After light polymerization, the indirect composite blocks were removed and Estenia air-barrier paste (Kuraray Dental) applied to all of their surfaces. Then the blocks were heatpolymerized at $160^{\circ} \mathrm{C}$, for $15 \mathrm{~min}$ in the same device. Then, those surfaces of the blocks which were to be cemented or bonded to the dentin were abraded with 50- $\mu$ m aluminum oxide (Korox, Bego, Bremen, Germany) at 2 atm pressure in the Topstar Z3 device (Bego).

\section{Bonding and Iuting procedures}

The application protocols and groups of the etching and bonding/luting agents for the indirect ceromers and direct composites are listed in Figure 1.

The following bonding/luting materials were used: (a) a etch-and-rinse adhesive system ( $5^{\text {th }}$ generation), Bond-1 Primer/Adhesive (Jeneric/ Pentron Incorporated, Wallingford, CT, USA) (b) a self-etch adhesive system ( $6^{\text {th }}$ generation), NanoBond Self-etch Primer and Adhesive (Jeneric/
Pentron Incorporated), and (c) a resin-based dental luting material, Cement-It (Jeneric/Pentron Incorporated). The three SRC's used were: (d) RelyX Unicem (3M ESPE, Seefeld, Germany), (e) Maxcem (Kerr, Orange, USA), and (f) Embrace Wet Bond (Pulpdent, Watertown, MA, USA) were used for bonding and luting procedures. A posterior composite resin, Alert (Jeneric Pentron Incorporated) was also used as a direct restoration material (control group).

The dentin surfaces for the etch-and-rinse adhesive system groups (groups 1 and 2) were etched with $37 \%$ phosphoric acid for $15 \mathrm{~s}$, washed and dried for $20 \mathrm{~s}$. Primer, adhesive and resin cement applications to dentin were performed following the manufacturers' directions. The adhesives were photoactivated for $20 \mathrm{~s}$ using a light-curing unit (Bluephase C5, Ivoclar Vivadent, Schaan, Liechtenstein) with light intensity of 600 $\mathrm{mW} / \mathrm{cm}^{2}$, as checked by a curing radiometer (Caulk Dentsply, Milford, DE, USA).

The composite resin (Alert) was cast in a Teflon mold in two increments and each increment was light-cured (Bluephase C5) for $40 \mathrm{~s}$ onto the pretreated dentin surface (Groups 1 and 3). Direct and indirect composite restorations (groups 2 and 4) were cemented with a resin cement (CementIt) after adhesive application to dentin surface. In Groups 5-7, the indirect composite blocks were pressed on the dual-cured self-adhesive cements (RelyX Unicem, Maxcem, Embrace Wet-Bond) onto the non-pretreated dentin surfaces under finger pressure for $30 \mathrm{~s}$, after which excess cement was removed. Light-curing was performed from 4 parallel directions along the cement interface for

\begin{tabular}{|c|c|c|c|}
\hline Groups & Dentin pretreatment & Bonding/luting agent & Restoration \\
\hline 1 (control gr.) & Etching $\left(37 \% \mathrm{H}_{2} \mathrm{PO}_{4}\right)$ & $5^{\text {th }}$ Generation Bonding (Bond-1 Primer/Adhesive) & $\begin{array}{l}\text { Direct composite } \\
\text { (Alert) }\end{array}$ \\
\hline 2 & Etching $\left(37 \% \mathrm{H}_{2} \mathrm{PO}_{4}\right)$ & $\begin{array}{l}\text { Bonding (Bond-1 Primer/Adhesive)+Resin Cement } \\
\qquad \begin{array}{c}\text { (Cement-It) } \\
\text { Resin Cement } \\
\text { (Cement-It) }\end{array}\end{array}$ & $\begin{array}{l}\text { Indirect composite } \\
\text { (Estenia) }\end{array}$ \\
\hline 3 & ------ & $\begin{array}{c}\text { Self-etch Adhesive System } \\
\text { (Nano-Bond SEP and Adhesive) }\end{array}$ & $\begin{array}{l}\text { Direct composite } \\
\text { (Alert) }\end{array}$ \\
\hline 4 & ------ & $\begin{array}{c}\text { Self-etch Adhesive System } \\
\text { (Nano-Bond SEP and Adhesive)+Resin Cement } \\
\text { (Cement-It) }\end{array}$ & $\begin{array}{l}\text { Indirect composite } \\
\text { (Estenia) }\end{array}$ \\
\hline 5 & ------ & $\begin{array}{l}\text { Self-Adhesive Resin Cement } \\
\text { (Rely X Unicem) }\end{array}$ & $\begin{array}{l}\text { Indirect composite } \\
\text { (Estenia) }\end{array}$ \\
\hline 6 & ------ & $\begin{array}{c}\text { Self-Adhesive Resin Cement } \\
\text { (Maxcem) }\end{array}$ & $\begin{array}{l}\text { Indirect composite } \\
\text { (Estenia) }\end{array}$ \\
\hline 7 & ------ & $\begin{array}{l}\text { Self-Adhesive Resin Cement } \\
\text { (Embrace Wet Bond) }\end{array}$ & $\begin{array}{l}\text { Indirect composite } \\
\text { (Estenia) }\end{array}$ \\
\hline
\end{tabular}

Figure 1- The tested materials and their respective application procedures 
$20 \mathrm{~s}$. The specimens were stored in distilled water at $37^{\circ} \mathrm{C}$ for $24 \mathrm{~h}$.

\section{Tensile bond strength testing and failure mode evaluation}

Tensile bond strength tests were performed on an Zwick testing device (Z010 model, Zwick GmbH,

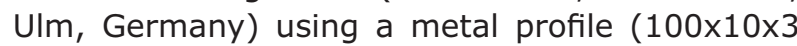
$\mathrm{mm}$ ) loading head $(50 \mathrm{~kg})$. Tests were performed at a constant speed of $1 \mathrm{~mm} / \mathrm{min}$ until the composite and indirect composite blocks were dislodged from the dentin surfaces. Bond strength was calculated in $\mathrm{MPa}$. The obtained tensile bond strength data were analyzed by the Student's t-test with level of significance of $p<0.05$. Statistical software was used for statistical data analysis (Version 11.0; SPSS Inc., Chicago, IL, USA).

Following tensile testing, two debonded specimens of each group (total 14 specimens) were randomly selected for SEM analysis. The surfaces were sputter coated with gold (BioRadSC502, Fison, U.K.) and observed with a scanning electron microscope (JEOL JSM-5200, Tokyo, Japan) operated at $20 \mathrm{kV}$. Dentin surfaces and the mode of fracture were viewed.

\section{RESULTS}

\section{Tensile bond test}

The tensile bond strengths (means and standard deviation, in $\mathrm{MPa}$ ) of the direct and indirect composites to dentin are shown in Table 1.

The direct composite resin restorations bonded with etch-and-rinse adhesive system (Group 1, control) exhibited the highest tensile bond strength (15.47 MPa), while the indirect composite luted with self-etch adhesive+resin cement (Group 4) exhibited the lowest strength (7.48 MPa).

The bond strengths of the direct and indirect composite restorations bonded with etch-andrinse adhesive systems (Groups 1 and 2) did not differ significantly ( $p>0.05 ; 15.47$ and $15.27 \mathrm{MPa}$, respectively).
The direct composite restoration bonded with etch-and-rinse adhesive system (Group 1) showed a higher bond strength than bonded with self-etch adhesive system (Group 3) (15.47 and 13.84 $\mathrm{MPa}$, respectively) although the difference was not statistically significant ( $p>0.05)$.

The indirect composite restorations bonded/ luted with etch-and-rinse adhesive system+resin cement (Group 2) had a significantly higher bond strength than those bonded/luted self-etch adhesive system+resin cement (Group 4) (15.26 and 7.48 $\mathrm{MPa}$, respectively) $(\mathrm{p}<0.05)$.

The direct composite restorations bonded with self-etch adhesive system (group 3) had a significantly higher bond strength than the indirect composite restorations bonded/cemented with selfetch adhesive+resin cement (Group 4) (13.84 and 7.48 $\mathrm{MPa}$, respectively) $(\mathrm{p}<0.05)$.

Among the indirect composite restorations cemented with SRCs (groups 5-7), Embrace Wet Bond (Group 7) (15.02 MPa) had the highest and Maxem (group 6) the lowest bond strength (13.23 MPa) $(p<0.05)$.

\section{Failure mode evaluation}

The surfaces of all specimens showed evidence of both adhesive and cohesive failure.

In Group 1 (etch-and-rinse adhesive system+direct composite restoration), adhesive failure was primarily observed at the dentin-bonding substrate interface and cohesive failure within the composite resin, and over open dentin tubules.

In Group 2 (etch-and-rinse adhesive system+resin cement+indirect composite block), adhesive failure was observed between resin cement-bonding and dentin-bonding interface, and also smear layer on the dentin surface.

In Group 3 (self-etch adhesive system+direct composite restoration), adhesive failure occurred between the dentin-bonding substrate, cohesive failure within the composite resin, and smear layer on the dentin surface.

In Group 4 (self-etch adhesive system+resin

Table 1- Tensile bond strength means (MPa) and standard deviations (SD) of direct and indirect composite restoration bonded/luted to dentin

\begin{tabular}{|c|c|c|}
\hline Groups & Bond Strength & $\mathbf{n}$ \\
\hline & Mean \pm SD & \\
\hline 1 (Total-etch adhesive $\rightarrow$ Direct Composite) & $15.47 \pm 2.05$ & 10 \\
\hline 2 (Total-etch adhesive+Resin Cement $\rightarrow$ Indirect composite) & $15.26 \pm 2.46$ & 10 \\
\hline 3 (Self-etch adhesive $\rightarrow$ Direct Composite) & $13.84 \pm 2.95$ & 10 \\
\hline 4 (Self-etch adhesive+Resin Cement $\rightarrow$ Indirect composite) & $7.48 \pm 2.58$ & 10 \\
\hline 5 [Self-adhesive resin cement (RelyX Unicem) $\rightarrow$ Indirect composite] & $14.40 \pm 2.61$ & 10 \\
\hline 6 [Self-adhesive resin cement (Maxcem) $\rightarrow$ Indirect composite] & $13.23 \pm 3.68$ & 10 \\
\hline 7 [Self-adhesive resin cement (Embrace Wet Bond) $\rightarrow$ Indirect composite] & $15.02 \pm 2.63$ & 10 \\
\hline
\end{tabular}


cement+indirect composite block), adhesive failure occurred between indirect composite blockresin cement substrate and resin cement-bonding interfaces, cohesive failure within the resin cement.

In Groups 5, 6 and 7 (SRCs+indirect composite blocks), adhesive failure occurred at the indirect composite block-SRC interface and cohesive failures within the SRCs.

\section{DISCUSSION}

Dentin-adhesive resins were originally formulated with separate etchants, primers, and adhesives, but they have evolved such that in some products the adhesive and primer are combined, in others the etchant and primer are combined, whereas in some, all 3 are combined. The latter 2 categories are considered "self-etch", but products in the last category have been termed "self-etch adhesives". Whether self-etch products are equivalent to earlier systems with separate etchants, also termed "etch-and-rinse" or "total-etch" systems, has not been established" ${ }^{5}$. Nano-Bond self-etch adhesive, evaluated in the present study, has etchant, primer, and adhesive combined into a single component, allowing the resin restorative material to be placed more quickly than with other types of bonding agents. All self-etch products have the advantage of producing little discomfort when applied to unanesthetized but sensitive dentin, because rinsing and air drying are unnecessary. Some of the limitations of the self-etch adhesive tested include the following: no capability for dual polymerization, which can be desirable for indirect adhesive restorations, and difficulty in preventing the acid resin from splashing onto adjacent teeth or soft tissue during air-drying. Castro, et al. ${ }^{7}$ (2007) concluded that the self-etch adhesive system was significantly more efficient in dentin than in enamel, while the one-bottle system was significantly more efficient in enamel when compared to the self-etch adhesive system.

The dual-polymerizing resin cement, CementIt, can be polymerized by light or by chemical polymerization. These two polymerizing mechanisms form the basis for the wide spread use of these luting materials for definitive cementation of all-ceramic as well as composite and metal-based indirect restorations. Furthermore, dual polymerizing resin cements are characterized by high mechanical strength and excellent esthetic properties. Their chemical composition allows adherence to the different dental substrates. However, resin cements require skillful handling, especially during the timeconsuming bonding procedure, and when removing excess cement. The use of resin cements in clinical practice is complicated and technique-sensitive ${ }^{24}$.

Some self-adhesive, dual-polymerizing universal resin cements (RelyX Unicem, Maxcem, and Embrace Wet Bond) have been recently introduced. The objective in developing these cements were to combine ease of handling (no pretreatment steps required) offered by glass ionomer cements with the favorable mechanical properties, attractive esthetics, and good tooth adhesion of resin cements. According to the manufacturers, bonding to tooth structure can be achieved without any pretreatment steps, for example, without etching, priming, or bonding. These self-adhesive universal resin cements are based on a new monomer, filler, and initiator technology. The manufacturer purports that the organic matrix consists of newly developed multifunctional phosphoric-acid methacrylates. The phosphoric-acid groups of these molecules condition the tooth surface and contribute to adhesion ${ }^{24}$.

The results of the present study showed that the restorations luted with SRCs had high tensile bond strengths and also revealed pronounced differences among the adhesives in their bonding performance on dentin, with the general trend that conventional systems with separate primers and bonding agents perform better than simplified systems that combine the functions of priming and bonding, and not so much on whether they are etch-and-rinse or self-etch approach type materials. These results are in line with the data from literature $8,12,20,23,25,29,30$. However, the bond strengths obtained in these studies and in the present investigation were lower than those expected (20 $\mathrm{MPa})^{10}$, which is the strength required to resist the stress generated by the polymerization shrinkage. However, comparison among studies performed with different methods was quite difficult ${ }^{9}$, with adhesion data for dentin bonding systems in the literature sometimes differing widely, even for the same dentin-bonding systems. The problem of bond testing is that materials are seldom compared with a standard, and experimental conditions often vary. Shear tests have produced higher bond strength than tensile bond tests ${ }^{6,22}$. Della Bona and Van Noort ${ }^{9}$ (1995), using finite element analysis, concluded that shear tests were more indicative of the cohesive resistance of the material and tensile tests of interface adhesion. Shear strengths are strongly influenced by material properties. Therefore, as the purpose of this study was to evaluate the adhesive capacity of the materials rather for example than the stress produced during clinical function, a tensile test was used. Also, the error-rates method showed that type and wideness of the tooth substrate affected the bond strength of the tested bonding/luting systems ${ }^{1}$. Therefore, in the present study, the tensile test was used rather than microtensile test.

The stresses at the interface of restorations are complex; but can be identified as mainly a 
tensile or shear type of stress, created either by forces working perpendicular to or parallel to the tooth surface ${ }^{13,20}$. Since the restorative materials evaluated are usually used in luting/cementing the inlay-onlays/crowns, the forces of displacement tend to be closer to that of the tensile test. Therefore, in the present study, a conventional tensile bond test was used. However, intraorally, indirect restorations are subject to different forces such as tensile, shear, compressive, oblique, and combinations of these types. This study evaluated only tensile forces. It is extremely difficult to duplicate in vitro forces because of the various movements of the mandible and different masticatory patterns. It is also difficult to reproduce the intraoral environment because conditions inside the mouth vary considerably, depending on the eating habits of the individual ${ }^{8}$. Thermocycling is one method used in several in vitro studies to simulate oral conditions, but it is not truly representative (see below).

Bond quality, however, should not be assessed on strength data alone because the failure mode is also important; this information may yield predictions of clinical performance, as several fracture patterns ${ }^{18}$ act under clinical conditions ${ }^{24}$. Failure analysis revealed adhesive modes at the dentin-bonding, resin cement-bonding, indirect composite block-resin cement, and indirect composite block-SRC substrate interfaces and cohesive modes within the resin cement, SRCs, and composite resin. Cohesive failure was not observed within the indirect composite blocks.

Although thermocycling does seem to be a valid in vitro method to accelerate the aging of restorative materials, it was not performed in this study, because the thermocycling regimens used in reported studies differ with respect to the number of cycles, temperature, and dwell time (immersion of specimens in hot and cold fluids). Reported numbers of cycles ranges from 100 up 50,000, which usually being arbitrarily set makes it difficult to compare published results. It is estimated that approximately 10,000 thermal cycles correspond to 1 year of clinical function. This estimate is based on the hypothesis that such cycles might occur 20 to 50 times a day, which makes the 500 -cycle regimen proposed by the ISO standard (ISO TR11450) insufficient to simulate the long-term challenging of bond durability. Several reports that used ISO protocol concluded that thermocycling did not affect the bond strength and microleakage of adhesive systems ${ }^{2}$. Abo-Hamar, et al. ${ }^{1}$ (2005) also reported that thermocycling did not significantly affect the bond strength of the tested luting systems (RelyX Unicem-RXU, Syntac/Variolink II, Panavia F2.0, Dyract Cem Plus, Ketac Cem-TetC) to dentin, whereas it significantly affected their bond strengths to enamel. Thermocycling and the resulting thermal stresses significantly decreased the bond strength of RXU and KetC to enamel. Amaral, et al. ${ }^{3}$ (2008) found that the degradation of resin-dentin bonds by the storage of specimens in water combined with thermocycling produced negative effects (decreased of adhesion) on microtensile bond strength after six months of water storage combined with 12,000 thermal cycles in the bur-prepared group. They and Osorio, et al. ${ }^{21}$ (2008) discussed this as follows: chemical reactions have been responsible for the degradation of resin-dentin bonds over time and, consequently, decrease in bond strength, including the loss of stability of the adhesive systems and the extraction of resin-material from the hybrid layer. Also, a fall in bond strength has been ascribed to the hydrolysis of the adhesive and collagen fibrils at the base of the hybrid layer, thereby weakening the physical properties of the resin-dentin bond. This process is accelerated by heat and repetitive contraction/expansion stresses generated at the tooth-resin interface during thermocycling. Amaral, et al. ${ }^{2}$ (2007) reported that the effect of mechanical loading to bonded interface is still unclear. Therefore, some investigations have combined thermal and mechanical cycling to explain hox degradation and to give more details about the performance of adhesive systems. When thermal and mechanical load cycling were performed concomitantly, a significant decrease in microtensile bond strength of an etch-and-rinse adhesive to dentin was observed in comparison to specimens that were thermocycled or submitted to mechanical loading alone. It is likely that the effect of loading is accelerated by thermocycling. Frankenberger and Tay $^{14}$ (2005) also concluded that the functional cavity test clearly showed that all adhesives performed very well initially in their capacity to compensate for shrinkage stresses.

Finger pressure was used during the luting of indirect composite blocks onto the tooth specimens. This may have resulted in an uneven amount of force during seating; however, this technique was chosen, as it simulates clinical methodology.

The present comparative in vitro study provided an immediate assessment of the bond created between the SRC and indirect composite restorative materials. However, in vitro tests cannot adequately simulate clinical conditions in every detail. Additional clinical factors, such as the retentive and resistance form of the preparation, were not considered. The results of in vitro tests should be applied to the clinical situation with caution although they can be used for comparison with other in vitro results obtained under identical conditions. The final evaluation of the performance of these materials should be determined using long-term clinical studies. 


\section{CONCLUSIONS}

Within the limitations of this in vitro study, the following conclusions may be drawn:

The etch-and-rinse adhesive system, Bond 1 primer/adhesive, produced the highest tensile bond strength to direct composite restoration onto the dentin, while the self-etch adhesive, NanoBond+resin cement, Cement-It produced the lowest bond strength.

Etch-and-rinse adhesive systems showed higher tensile bond strength than self-etch adhesive systems.

Among the SRCs, Embrace Wet Bond produced the highest bond strength.

Cohesive failure was observed within the composite resin restorations, but it was not observed within the indirect composite restorations.

\section{REFERENCES}

1- Abo-Hamar SE, Hiller KA, Jung H, Federlin M, Friedl KH, Schmalz $\mathrm{G}$. Bond strength of a new universal self-adhesive resin luting cement to dentin and enamel. Clin Oral Invest. 2005;9:161-7. 2- Amaral FLB, Colucci V, Palma-Dibb RG, Corona SAM. Assessment of in vitro methods used to promote adhesive interface degradation: a critical review. J Esthet Restor Dent. 2007; 19:340-54.

3- Amaral FLB, Colucci V, Souza-Gabriel AE, Chinelatti MA, Palma Dibb RG, Corona SAM. Adhesion to Er:YAG laser-prepared dentin after long-term water storage and thermocycling. Oper Dent. 2008;33:51-8.

4- Ateyah NZ, Elhejazi AA. Shear bond strengths and microleakage of four types of dentin adhesive materials. J Contemp Dent Pract. 2004;5:63-73.

5- Brackett WW, Haisch LD, Pearce MG, Brackett MG. Microleakage of Class $\mathrm{V}$ resin composite restorations placed with self-etching adhesives. J Prosthet Dent. 2004;91:42-5.

6- Cardoso PEC, Braga RR, Carrilho MRO. Evaluation of microtensile, shear and tensile tests determining the bond strength of three adhesive systems. Dent Mater. 1998;14:394-8.

7- Castro CG, Santos Filho PC, Mota AS, Campos RE, Soares $\mathrm{C}$. Effect of a bonding resin layer associated with a self-etching adhesive system on the bond strength of indirect restorations. J Appl Oral Sci. 2007;15:94-8.

8- Chang JC, Hart DA, Estey AW, Chan JT. Tensile bond strengths of five luting agents to two CAD-CAM restorative materials and enamel. J Prosthet Dent. 2003;90:18-23.

9- Della Bona A, Van Noort R. Shear vs tensile bond strength of resin composite bonded to ceramic. J Dent Res. 1995;74:1591-6. 10- Eick JD, Gwinnett AJ, Pashley DH, Robinson SJ. Current concepts on adhesion to dentin. Crit Rev Oral Biol Med. 1997;8:306-35.

11- El-Mowafy $\mathrm{O}$. The use of resin cements in restorative dentistry to overcome retention problems. J Can Dent Assoc. 2001;67:97102.

12- Ergin S, Gemalmaz D. Retentive properties of five different luting cements on base and noble metal coping. J Prosthet Dent. 2002;88:491-7.
13- Ernst CP, Cohnen U, Stender E, Willerhausen B. In vitro retentive strength of zirconium oxide ceramic crowns using different luting agents. J Prosthet Dent. 2005;93:551-8.

14- Frankenberger R, Tay FR. Self-etch vs etch-and-rinse adhesives: effect of thermo-mechanical fatigue loading on marginal quality of bonded resin composite restorations. Dent Mater. 2005;21:397-412.

15- Gerdolle DA, Mortier E, Loos-Ayav C, Jacquot B, Panighi MM. In vitro evaluation of microleakage of indirect composite inlays cemented with four luting agents. J Prosthet Dent. 2005;93:56370.

16- Hikita K, Van Meerbeek B, De Munck J, Ikeda T, Van Landuyt $\mathrm{K}$, Maida $\mathrm{T}$, et al. Bonding effectiveness of adhesive luting agents to enamel and dentin. Dent Mater. 2007;23:71-80.

17- Hogan LC, Burrow MF. The microtensile strength of bonding resins. Aust Dent J. 2001;46:194-7.

18- Kitasako Y, Burrow MF, Katahira N, Nikaido T, Tagami J. Shear bond strength of three resin cements to dentine over 3 years in vitro. J Dent. 2001;29:139-44.

19- Maurin JC, Lagneau C, Durand M, Lissac M, Seux D. Tensile and shear bond strength evaluation of a total-etch three-step and two self-etching one-step dentin bonding systems. J Adhes Dent. 2006;8:27-30.

20- Mota CS, Demarco FF, Camacho GB, Powers JM. Tensile bond strength of four resin luting agents bonded to bovine enamel and dentin. J Prosthet Dent. 2003;89:558-64.

21- Osorio R, Pisani-Proença J, Erhardt MCG, Osorio E, Aguilera FS, Tay FR, et al. Resistance of ten contemporary adhesives to resin-dentine bond degradation. J Dent. 2008;36:163-9.

22- Pecora N, Yaman P, Dennison J, Herrero A. Comparison of shear bond strength relative to two testing devices. J Prosthet Dent. 2002:88;511-5.

23- Perdigao J, Gomes G, Gondo R, Fundingsland JW. In vitro bonding performance of all-in-one adhesives. Part 1 - microtensile bond strengths. J Adhes Dent, 2006;8:367-73.

24- Piwowarczyk A, Laurer HC, Sorensen JA. In vitro shear bond strength of cementing agents to fixed prosthodontic restorative materials. J Prosthet Dent. 2004;92:265-73.

25- Sengun A, Ünlü N, Öztürk B, Özer F. Microtensile bond strength of two resin composite materials placed with direct and indirect techniques under simulated pulpal pressure. J Adhes Dent. $2005 ; 7: 197-202$.

26- Shimada Y, Iwamoto N, Kawashima M, Burrow MF, Tagami J. Shear bond strength of current adhesive systems to enamel, dentin and dentin-enamel junction region. Oper Dent. 2003;28:585-90. 27- Soares CJ, Giannini M, Oliveira MT, Paulillo LAMS, Martins LRM. Effects of surface treatments of laboratory-fabricated composites on the microtensile bond strength to a luting resin cement. J Appl Oral Sci. 2004; 12:45-50.

28- Swift EJ, Sturdevant JR, Ritter AV. Class I and II indirect tooth-colored restorations. In: Roberson TM, Heymann HO, Swift EJ Jr, editors. Art and science of operative dentistry. $5^{\text {th }}$ ed. Saint Louis: Mosby; 2006. p.603-22.

29- Uy JN, Lian JN, Nicholls JI, Tan KB. Load-fatigue performance of gold crowns luted with resin cements. J Prosthet Dent. 2006;95:315-22.

30- Üşümez A, Aykent F. Bond strengths of porcelain laminate veneers to tooth surfaces prepared with acid and $\mathrm{Er}, \mathrm{Cr}$ :YSGG laser etching. J Prosthet Dent. 2003;90:24-30. 